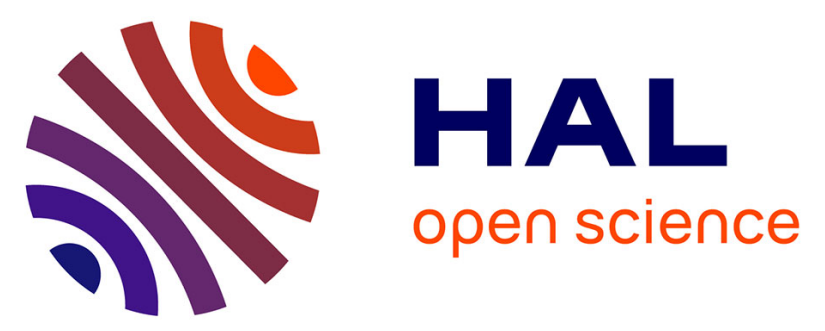

\title{
Multicolor-FISH Characterization of a Prenatal Mosaicism for a Chromosomal Rearrangement Undetected by Molecular Cytogenetics
}

Laura Mary, Philippe Loget, Sylvie Odent, Dominique Aussel, Gwenaëlle Le Bouar, Erika Launay, Catherine Henry, Marc-Antoine Belaud-Rotureau,

Sylvie Jaillard

\section{To cite this version:}

Laura Mary, Philippe Loget, Sylvie Odent, Dominique Aussel, Gwenaëlle Le Bouar, et al.. MulticolorFISH Characterization of a Prenatal Mosaicism for a Chromosomal Rearrangement Undetected by Molecular Cytogenetics. Cytogenetic and Genome Research, 2021, 161 (3-4), pp.143-152. 10.1159/000514592 . hal-03215883

\section{HAL Id: hal-03215883 \\ https://hal.science/hal-03215883}

Submitted on 12 Jul 2021

HAL is a multi-disciplinary open access archive for the deposit and dissemination of scientific research documents, whether they are published or not. The documents may come from teaching and research institutions in France or abroad, or from public or private research centers.
L'archive ouverte pluridisciplinaire HAL, est destinée au dépôt et à la diffusion de documents scientifiques de niveau recherche, publiés ou non, émanant des établissements d'enseignement et de recherche français ou étrangers, des laboratoires publics ou privés. 
2 Multicolor-FISH characterization of a prenatal mosaicism for a chromosomal rearrangement undetected

3 by molecular cytogenetic

4 Laura Mary ${ }^{1,2,3}$, Philippe Loget ${ }^{2}$, Sylvie Odent ${ }^{4}$, Dominique Ausse $\left.\right|^{5}$, Gwénaelle Le Bouar ${ }^{6}$, Erika Launay ${ }^{1}$,

5 Catherine Henry ${ }^{1}$, Marc-Antoine Belaud-Rotureau ${ }^{1,3}$, Sylvie Jaillard ${ }^{1,3}$

6

$7 \quad{ }^{1}$ Service de Cytogénétique et Biologie Cellulaire, CHU Rennes, Rennes, France

$8 \quad{ }^{2}$ Service d'Anatomie et Cytologie Pathologiques, CHU Rennes, Rennes, France

9 3Université Rennes 1, INSERM, EHESP, IRSET - UMR_S 1085, Rennes, France

$10{ }^{4}$ Service de Génétique Clinique, CHU Rennes, CLAD Ouest, Rennes, France

$11{ }^{5}$ Service de Gynécologie-Obstétrique, Clinique de La Sagesse, Rennes, France

12 Unité de Médecine fœtale, Service de Gynécologie-Obstétrique, CHU Rennes, Rennes, France

Short Title: Multicolor-FISH characterization of a prenatal low-level mosaicism chromosomal rearrangement.

Corresponding author:

18 Dr. Laura Mary, laura.mary@chu-rennes.fr

19 Service de Cytogénétique et Biologie Cellulaire

20 CHU Pontchaillou

212 rue Henri Le Guilloux

35000 RENNES, France

23

Phone: +3329928 8338

24

Number of Tables: 0

26

Number of Figures: 4

27

Word count: 3046 (main body text)

28

29

Keywords: Multicolor-FISH; prenatal; mosaicism; aCGH; chromosome rearrangement 


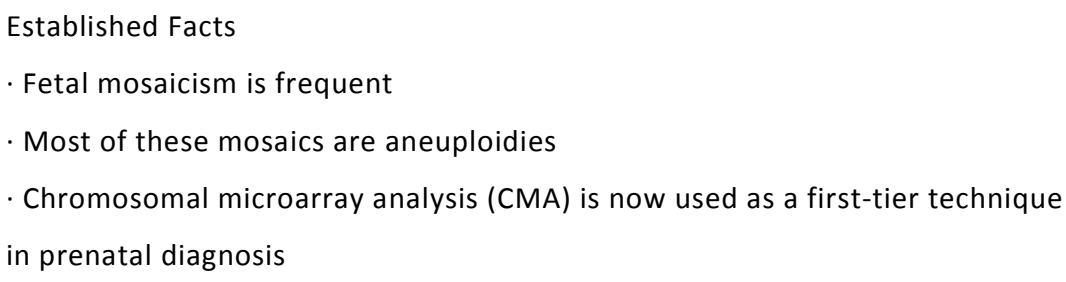

\section{ABSTRACT}

Fetal mosaicism for chromosomal rearrangements remains a challenge to diagnose, even in the era of whole genome sequencing. We present here a case of fetal mosaicism for a chromosomal rearrangement explored in amniocytes and fetal muscle, consisting of a major cell population (95\%) with 4q partial monosomy and a minor population (5\%) with additional material replacing the 4qter deleted segment. Molecular techniques (MLPA, array-CGH) failed to assess the origin of this material. Only multicolor-FISH identified the additional segment on chromosome 4 as derived from chromosome 17 . Due to the poor prognosis, the couple chose to terminate the pregnancy. Because of low-level mosaicism, chromosomal microarray analyses (CMA), now considered as first-tier prenatal genetic analysis, did not allow the identification of the minor cell. In case of large CNV $(>5 \mathrm{Mb})$ detected by CMA, realization of a karyotype may be considered to elucidate the mechanism of the underlying rearrangement and eliminate mosaicism.

\section{I) INTRODUCTION}

Fetal mosaicism (i.e. the presence, in an individual, of two or more distinct cellular populations) can concern $0.64 \%$ of amniotic fluid samples (AFS) and up to $2 \%$ of chorionic villus samples (CVS) (Grati et al., 2017). For these CVS, most of mosaicisms are confined to the placenta (Grati et al., 2017), and only fetal sampling (e.g. AFS or cord blood samples) can prove true fetal mosaicism (Malvestiti et al., 2015). Mosaicism can also be the consequence of culture artifacts (Pipiras et al., 2004). Most fetal mosaicisms are aneuploidies (Grati et al., 2017) corresponding to mitotic, post-zygotic events, mainly underpinned by two mechanisms: chromosome missegregation in a somatic cell of a euploid conceptus and trisomy or monosomy rescue after a meiotic nondisjunction (Grati et al., 2017; Taylor et al., 2014). Mosaicism for small supernumerary marker chromosomes (sSMCs) are also described in prenatal samples and are involved in $14 \%$ of fetal mosaicisms (Grati et al., 2017). Mosaicism may finally also involve structural chromosomal abnormalities and thus are observed for balanced or unbalanced translocations (Malvestiti et 
al., 2015; Pipiras et al., 2004; Stallings et al., 1997). Mosaicism remains a challenge to diagnose, even with routine techniques of prenatal testing. When diagnosed, the clinical consequences of such mosaicisms are also highly difficult to predict, depending both on the anomalies involved and the level of mosaicism in each tissue (Taylor et al., 2014).

Among cytogenetic techniques, multicolor-FISH (M-FISH), consisting in using up to 24 chromosome painting probes in a single FISH technique is overthrown by molecular techniques such as chromosomal microarray analyses (CMA) or high throughput sequencing. However, M-FISH is still of interest to supplement these techniques in some cases, such as characterizing small supernumerary marker chromosomes (sSMC,(Jang et al., 2016)) or mosaic complex chromosomal rearrangements (Lin et al., 2018).

We present here a case-report of a fetal mosaicism for an unexpected unbalanced translocation solved by M-FISH after failure of both MLPA and CMA to conclude on the complete nature of the rearrangement.

\section{II) CLINICAL REPORT}

\section{II.1) Case Presentation}

A 28 year-old primigravida woman was referred to our center at 15 gestation weeks (GW) for an isolated increased nuchal translucency $\left(95^{\text {th }}\right.$ percentile). Familial and personal medical histories were unremarkable. Consanguinity was discounted. Amniotic fluid was sampled to find a possible genetic caused of the increased nuchal translucency.

\section{II.2) Methods and Results}

RHG -banding karyotype was performed on cultured amniocytes (for the fetus) and cultured lymphocytes obtained from peripheral blood (for the parents) according to standard cytogenetic procedures. Two abnormal cell populations were observed on both fetal karyotypes realized on two different amniotic fluid samples (performed at 15 gestation weeks (GW) and $23 \mathrm{GW}$ respectively): one major population (95\% of cells) carrying a distal deletion of the long arm of a chromosome 4 (Figure $1 \mathrm{~A})$, and a second population ( $5 \%$ of cells) presenting with additional material of unknown origin on the deleted chromosome 4 (Figure 1B). No normal cell was observed. FISH was performed using chromosome 4 whole chromosome painting and subtelomeric probes on cultured amniocytes according to manufacturers' protocols. FISH confirmed that the subtelomeric 4qter region was deleted in both populations and that the additional material did not originate from a chromosome 4 (data not shown). To identify the additional chromosomal material, different molecular techniques were used. DNA was extracted from cultured amniocytes. The MLPA kits SALSA P036B and P070 (MRC Holland, Amsterdam, The Netherlands) were used according to the manufacturer's protocol. Electrophoresis of the PCR products was run on an AbiPrism 3130xl and analyzed using Coffalyser.Net software. This analysis showed a homogeneous heterozygous deletion of chromosome 4 long arm subtelomeric region and failed to detect a gain of another subtelomeric region (data not shown).

Oligonucleotide array-CGH (aCGH) was performed using the Agilent Human Genome CGH microarray 4x180K (Agilent Technologies, Santa Clara, CA, USA), on DNA extracted from both cultured amniocytes and 
frozen fetal muscle. Scanning, extraction and analysis methods were described elsewhere (Jaillard et al., 2011). The probes were mapped using GRCh37 genome version. Aberration detection was set as follow: minimal number of deviated probes $=3$, with ADM-2 as aberration algorithm (threshold $=6$ ) with fuzzy zero off. aCGH on both samples highlighted a terminal deletion starting at 4q33 and spanning 19.9Mb (Figure $2 \mathrm{~A})$. The mean log ratio of the deletion was -0.92 , a result in favor of a homogeneous heterozygous 4q33q35.2terminal deletion. The profiles of the other chromosomes showed no pathogenic gain, even in mosaic (assessed through multisample analyses).

Parental karyotypes were normal.

Due to the difficulties in identifying the additional material on fetal chromosome $4 q$ with MLPA and aCGH, an M-FISH on cultured amniocytes was performed using the 24Xcyte-MetaSystems 24-color kit and according to the manufacturer's protocol. Counting 100 metaphases, we finally concluded that the additional material, present in 5\% of the metaphases, originated from chromosome 17 (Figure 3B). In 95\% of the metaphases, we only observed the terminal $4 \mathrm{q}$ deletion.

Retrospective analysis of the karyotype in light of the M-FISH findings suggested that the additional material corresponded to the long arm of a chromosome 17. Reanalysis of the aCGH profiles of chromosome 17 did not show any deviation (Figure 2B). We performed an additional FISH analysis using the ZytoLight ${ }^{\circledR}$ ERBB2/CEP17 probes (Zytovision GmBH, Bremerhaven, Germany) on frozen fetal muscle. Mosaicism for partial trisomy $17 q$ was estimated to be $7-8 \%$ in this tissue. In all the cells carrying an extra signal of the ERBB2 probe (at 17q12q21.1 locus) we did not identify additional spots for the probe targeting the chromosome 17 centromere. Thus, these results discounted the presence of centromere of chromosome 17 in the additional segment of chromosome 17 located on 4q. In conclusion, the fetal karyotype presented with a major cellular population showing a terminal deletion 4q33qter (95\% of cells), and a minor population showing the same 4q33qter deletion, replaced by a chromosome 17 long arm (5\% of cells) leading to chromosome 17 partial trisomy. Both populations were otherwise disomic for normal chromosomes 17. The final formula was $\operatorname{mos} 46, X Y, \operatorname{del}(4)(q 33)[95] / 46, X Y, \operatorname{der}(4) t(4 ; 17)(q 33 ; q 11)[5] . \operatorname{arr}[G R C h 37]$ 4q33q35.2(170684863_190679684)x1

\section{II.3) Pregnancy outcome}

Due to the poor prognosis resulting from the chromosomal anomalies, the couple chose to terminate the pregnancy at $24 \mathrm{GW}$. A male fetus was delivered. He presented with a dolichocephaly associated with prefrontal edema, hypertelorism, retrognathism and a narrow palate. Careful examination of the extremities highlighted brachymesophalangia of the $5^{\text {th }}$ fingers and a bilateral single palmar crease. At autopsy, the fetus also had a single left umbilical artery, cryptorchidism, a common mesentery with an intestinal malrotation and a small atrial septal defect. Delayed bone maturation (bone maturation compatible with a $22 \mathrm{GW}$-old fetus) was diagnosed at standard radiographies. Histopathological analyses 
revealed asymmetric testes, with one normal testis and one showing an immature parenchyma. Histological analyses of the other organs were unremarkable.

\section{III) DISCUSSION}

Mosaicism in prenatal samples is a phenomenon favored by advanced parental age (Taylor et al., 2014) that can reach up to $2 \%$ of CVS samples (Grati et al., 2017) but is more uncommon in AFS (between $0.3 \%$ and 0.64\% (Grati et al., 2017; Ing et al., 1999; Li et al., 2019; Ll et al., 2019)). Most of these mosaicisms, especially when confirmed on fetal-derived tissues, are aneuploidies (Grati et al., 2017). However, some of these mosaic anomalies may involve structural chromosomal abnormalities. If most of these anomalies are sSMCs, mosaicism for balanced or unbalanced translocations are also observed (Pipiras et al., 2004; Stallings et al., 1997). We present here a case of mosaicism in a fetus presenting with a major cell population showing a $4 q$ partial monosomy and a minor population with a $4 q$ partial monosomy plus a $17 q$ partial trisomy.

$4 q$ terminal deletions are rare and responsible for various phenotypes, combining cleft lip and palate, congenital heart defects and neurodevelopmental delay, as well as other minor anomalies depending on the size of the deletion (Tidrenczel et al., 2019). Large 17q duplications are also very rare and seem to generate more severe phenotypes, as Ellis-Van-Creveld-like features (Serotkin et al., 1988), delayed psychomotor development, micrognathia, skeletal anomalies, and central nervous system (CNS) defects and even hydrops fetalis (Lenzini et al., 1988). The fetus presented here had an association of several mild anomalies including facial dysmorphism, single left umbilical artery, cryptorchidism intestinal malrotation and small atrial septal defect. This phenotype may recall $4 q$ terminal deletion syndrome rather than $17 q$ duplication. This may be explained by the very low prevalence of cells carrying a 17q trisomy contrary to homogeneous 4qter deletion.

The threshold of mosaicism detection for prenatal cytogenetic techniques is around $19 \%$ for karyotype (for a routine number of 15 metaphases analyzed, with 95\% degree of confidence, reaching $5 \%$ with 99\% degree of confidence if 100 cells are analyzed (Hook, 1977)), 40\% for MLPA (Chen et al., 2014) and 20\% for BoBs (BACs on Beads,(Cheng et al., 2013)). The use of CMA lowered the capacities of mosaic detection, and the sensitivity of this technique for both gains and losses is around 10\% (9-15\% (Ballif et al., 2006; Carey et al., 2014)).The lowest level of prenatal mosaicism detected previously reported in the literature was $6 \%$ in a case of trisomy 21 (detected through karyotype on amniocytes, (Sifakis et al., 2008)). In our case, karyotype identified 2 cell populations but MLPA and aCGH failed to identify the nature of the additional material located on chromosome $4 q$, because of a very low level of mosaicism for the cell line with the der(4)t(4;17) chromosome (5\%). Only M-FISH led to the identification of the additional material, corresponding to additional chromosome 17 long arm material on chromosome 4q. As previously mentioned, M-FISH is now used in rare pre- and postnatal cases of SSMC when CMA does not allow to characterize the abnormal chromosome (Jang et al., 2016), by painting all chromosomes in one experiment. However, M- FISH shows limitations when exact localization of a chromosomal breakpoint is required or intrachromosomal 
aberrations are present. Another limitation is the size of the chromosomal segment involved in a rearrangement. Apart from M-FISH, massive parallel sequencing MPS with Whole Genome Sequencing (WGS), is predicted helpful to shed light on chromosomal rearrangements but CNV smaller than 100 kb may still be challenging to diagnose in routine practice (Gross et al., 2019) and repetitive DNA sequences, such as centromeres, cannot be explored. Moreover, WGS detection threshold for mosaicism is estimated between 10 and 20\% depending on the anomaly (Hochstenbach et al., 2019), lower detection thresholds being currently achieved only for point variations through targeted MPS (Brewer et al., 2020; Liu et al., 2020). These statements suggest that MPS is probably not suitable for an accurate characterization of our rearrangement.

Chromosomal rearrangements are a common finding in early human embryos (Vanneste et al., 2009). These rearrangements include segmental terminal imbalances or double-strand breaks (DSB) within the centromeric regions, whole arm deletions and duplications. Multiple rearrangements can coexist in the same blastomere, revealing a high chromosomal instability (Vanneste et al., 2009). Most of these anomalies may be rescued through various mechanisms or be overwhelmed by normal cells (Popovic et al., 2020), but milder anomalies can persist and generate mosaicism (Grati et al., 2017). Four hypotheses can be formulated to elucidate the mechanism generating the rearrangement observed in our case (Figure 4). A) A balanced translocation (4;17)(q33;q11) appeared in one parent's gamete and the zygote received the der(4) chromosome. Then, during the early mitotic divisions of the embryo, a break occurred on the derivative chromosome with loss of the additional segment of $17 q$ attached to $4 q$. The broken der(4) is then stabilized by neotelomere formation, resulting in a minor "native" cell line with the der(4) and a major "derived" cell line with a pure 4q deletion (Figure 4A). This hypothesis has been proposed by (Kulikowski et al., 2006) as a statement for a similar mosaicism observed in a patient, which associated a pure monosomy 9p23pter in a major cell line and a minor cell line showing additional material from chromosome 1 (1q41qter) in place of the deleted 9p23pter segment. This hypothesis seems to be the most relevant to explain the results obtained in this case.

B) A DSB occurred at 4q33 during early embryogenesis. Microhomology Mediated Break-Induced Repair (MMBIR) mechanism took place to repair the DSB during replication. Briefly, MMBIR allows a collapsed replication fork to invade any single stranded template in close physical proximity that it shares microhomology to (Colnaghi et al., 2011). Here, instead of using a replication fork on chromosome 4 as a template to correct the DSB, the cell used a fork on chromosome 17, resulting in an aberrant chromosome 4 in which the 4q33q35 region is replaced by a segment originating from chromosome 17 (Figure 4B). These previous hypotheses may be promoted by the abundance of segmental duplications and Low-CopyRepeats (LCR) on chromosome 17 (Cardone et al., 2008), some of them having strong homologies with LCR on distal chromosome 4q. The presence of intrachromosomal telomeric-like sequences at both centromeric region of chromosome 17 and 4q32q33 band may favor telomere capture as a way to "heal" broken 
chromosomes but also chromosomal rearrangements and breakages (Ruiz-Herrera et al., 2005). The characterization of the breakpoints in the minor cell line would have been of interest to explore the hypothesis of the invasion of a chromosome 17 template by a collapsed fork on chromosome 4, but unfortunately, we did not have enough fetal material to do so.

C) A balanced translocation $(4 ; 17)(q 33 ; q 11)$ appears in early embryogenesis. The centromere of the chromosome 17 was included in the translocation leading to the generation of an acentric chromosome 17 derivative (lost during mitoses) and a dicentric chromosome 4 derivative. Endoreplication or similar mechanisms rescues the monosomy 17 (Taylor et al., 2014). Then, absence of centromere inactivation in some cells may result in a breakage of the chromosome 4 derivative during mitosis and thus to a pure 4q33qter-deleted population (Figure 4C). This hypothesis was discounted by complementary FISH analyses showing the absence of chromosome 17 centromere in the der(4) of the minor cell line.

D) Finally, it has also been recently demonstrated that chromoanagenesis may occur in the germline, resulting in high complexity rearrangements. These rearrangements are often stable, but rare cases of instability generating mosaicism are described. In an autistic patient, Collins et al. found a somatic mosaic unbalanced chromoanasynthesis of chromosome 19, resulting from a de novo duplication-inversionduplication in the germline (or in early embryogenesis) followed by mitotic missegregation leading to 6 mosaic duplications (Collins et al., 2017). Due to the extensive explorations performed, this hypothesis seems very unlikely (Figure 4D).

\section{IV) CONCLUSION}

Chromosomal mosaicism is frequent in prenatal period but remains a challenge to diagnose. After assessing the presence of a mosaicism in a fetal-derived sample, determining the nature of the chromosomal anomaly can raise unexpected issues, even in the era of WGS. For prenatal diagnosis, CMA analysis should now be considered as a gold standard technique performed in first tier, as recommended by the Association des Cytogénéticiens de Langue Française (ACLF) in some indications presented in the guidelines. Its limitations in detecting low-level mosaicisms is now well described but may be tolerated, given the fact that low-mosaic anomalies are very rare, thus chromosomal mosaic anomalies overlooked by CMA are estimated less than $1 \%$ (Tuke et al., 2019). However, the case reported here highlights the limitations of aCGH analysis for the detection of multiple abnormal cell lines and the necessity to associate morphological techniques with CMA (as karyotype or M-FISH) to conclude properly on the mechanism underlying the anomaly. In case of large CNV $(>5 \mathrm{Mb})$ detected by $\mathrm{CMA}$, the realization of a karyotype may be considered to elucidate the mechanism of the underlying rearrangement and eliminate low-level mosaicism.

\section{STATEMENTS}

\section{Acknowledgements}


We are grateful to Dr K. Pluquailec, who performed the initial karyotypes, and Dr D. D'Hervé who referred the patient.

\section{Statement of Ethics}

The research was conducted ethically in accordance with the World Medical Association Declaration of Helsinki. Written informed consent was obtained from the parents of the fetus for publication of this case report and any accompanying images.

\section{Conflict of Interest}

The authors have no conflicts of interest to declare.

\section{Funding sources}

This research did not receive any specific grant from funding agencies in the public, commercial, or not-forprofit sectors.

\section{Author Contributions}

SJ conceived and designed the study. SO, DA and GLB were involved in the patient care and evaluation. EL, $\mathrm{CH}$ and $\mathrm{LM}$ acquired the cytogenetic data. SJ, LM, CH and EL analyzed and interpreted the data. PL performed the fetal autopsy. LM wrote the manuscript. SJ and MABR critically reviewed the manuscript and all authors read and approved the final manuscript.

\section{REFERENCES}

Ballif, B.C., Rorem, E.A., Sundin, K., Lincicum, M., Gaskin, S., Coppinger, J., Kashork, C.D., Shaffer, L.G., Bejjani, B.A., 2006. Detection of low-level mosaicism by array CGH in routine diagnostic specimens. Am. J. Med. Genet. A. 140, 2757-2767. https://doi.org/10.1002/ajmg.a.31539

Brewer, C.J., Gillespie, M., Fierro, J., Scaringe, W.A., Li, J.M., Lee, C.-Y., Yen, H.-Y., Gao, H., Strom, S.P., 2020. The Value of Parental Testing by Next-Generation Sequencing Includes the Detection of Germline Mosaicism. J. Mol. Diagn. JMD 22, 670-678. https://doi.org/10.1016/j.jmoldx.2020.02.001

Cardone, M.F., Jiang, Z., D’Addabbo, P., Archidiacono, N., Rocchi, M., Eichler, E.E., Ventura, M., 2008. Hominoid chromosomal rearrangements on 17q map to complex regions of segmental duplication. Genome Biol. 9, R28. https://doi.org/10.1186/gb-2008-9-2-r28

Carey, L., Scott, F., Murphy, K., Mansfield, N., Barahona, P., Leigh, D., Robertson, R., McLennan, A., 2014. Prenatal diagnosis of chromosomal mosaicism in over 1600 cases using array comparative genomic hybridization as a first line test. Prenat. Diagn. 34, 478-486. https://doi.org/10.1002/pd.4332

Chen, X., Li, H., Mao, Y., Xu, X., Lv, J., Zhou, L., Lin, X., Tang, S., 2014. Subtelomeric multiplex ligationdependent probe amplification as a supplement for rapid prenatal detection of fetal chromosomal aberrations. Mol. Cytogenet. 7, 96. https://doi.org/10.1186/s13039-014-0096-1

Cheng, Y.K.Y., Wong, C., Wong, H.K., Leung, K.O., Kwok, Y.K., Suen, A., Wang, C.C., Leung, T.Y., Choy, K.W., 2013. The detection of mosaicism by prenatal BoBs ${ }^{\mathrm{TM}}$. Prenat. Diagn. 33, 42-49. https://doi.org/10.1002/pd.4006

Collins, R.L., Brand, H., Redin, C.E., Hanscom, C., Antolik, C., Stone, M.R., Glessner, J.T., Mason, T., Pregno, G., Dorrani, N., Mandrile, G., Giachino, D., Perrin, D., Walsh, C., Cipicchio, M., Costello, M., Stortchevoi, A., An, J.-Y., Currall, B.B., Seabra, C.M., Ragavendran, A., Margolin, L., Martinez-Agosto, J.A., Lucente, D., Levy, B., Sanders, S.J., Wapner, R.J., Quintero-Rivera, F., Kloosterman, W., Talkowski, M.E., 2017. Defining the diverse spectrum of inversions, complex structural variation, and chromothripsis in the morbid human genome. Genome Biol. 18. https://doi.org/10.1186/s13059-017-1158-6 
Colnaghi, R., Carpenter, G., Volker, M., O'Driscoll, M., 2011. The consequences of structural genomic alterations in humans: genomic disorders, genomic instability and cancer. Semin. Cell Dev. Biol. 22, 875-885. https://doi.org/10.1016/j.semcdb.2011.07.010

Grati, F.R., Malvestiti, F., Branca, L., Agrati, C., Maggi, F., Simoni, G., 2017. Chromosomal mosaicism in the fetoplacental unit. Best Pract. Res. Clin. Obstet. Gynaecol. 42, 39-52. https://doi.org/10.1016/j.bpobgyn.2017.02.004

Gross, A.M., Ajay, S.S., Rajan, V., Brown, C., Bluske, K., Burns, N.J., Chawla, A., Coffey, A.J., Malhotra, A., Scocchia, A., Thorpe, E., Dzidic, N., Hovanes, K., Sahoo, T., Dolzhenko, E., Lajoie, B., Khouzam, A., Chowdhury, S., Belmont, J., Roller, E., Ivakhno, S., Tanner, S., McEachern, J., Hambuch, T., Eberle, M., Hagelstrom, R.T., Bentley, D.R., Perry, D.L., Taft, R.J., 2019. Copy-number variants in clinical genome sequencing: deployment and interpretation for rare and undiagnosed disease. Genet. Med. Off. J. Am. Coll. Med. Genet. 21, 1121-1130. https://doi.org/10.1038/s41436-018-0295-y

Hochstenbach, R., van Binsbergen, E., Schuring-Blom, H., Buijs, A., Ploos van Amstel, H.K., 2019. A survey of undetected, clinically relevant chromosome abnormalities when replacing postnatal karyotyping by Whole Genome Sequencing. Eur. J. Med. Genet. 62, 103543. https://doi.org/10.1016/j.ejmg.2018.09.010

Hook, E.B., 1977. Exclusion of chromosomal mosaicism: tables of $90 \%, 95 \%$ and $99 \%$ confidence limits and comments on use. Am. J. Hum. Genet. 29, 94-97.

Ing, P.S., Van Dyke, D.L., Caudill, S.P., Reidy, J.A., Bice, G., Bieber, F.R., Buchanan, P.D., Carroll, A.J., Cheung, S.W., Dewald, G., Donahue, R.P., Gardner, H.A., Higgins, J., Hsu, L.Y., Jamehdor, M., Keitges, E.A., Laundon, C.H., Luthardt, F.W., Mascarello, J., May, K.M., Meck, J.M., Morton, C., Patil, S., Peakman, D., Pettenati, M.J., Rao, N., Sanger, W.G., Saxe, D.F., Schwartz, S., Sekhon, G.S., Vance, G.H., Wyandt, H.E., Yu, C.W., Zenger-Hain, J., L. Chen, A.T., 1999. Detection of Mosaicism in amniotic fluid cultures: A CYT02000 collaborative study. Genet. Med. 1, 94-97. https://doi.org/10.1097/00125817-199903000-00006

Jaillard, S., Andrieux, J., Plessis, G., Krepischi, A.C.V., Lucas, J., David, V., Le Brun, M., Bertola, D.R., David, A., Belaud-Rotureau, M.-A., Mosser, J., Lazaro, L., Treguier, C., Rosenberg, C., Odent, S., Dubourg, C., 2011. 5q12.1 deletion: delineation of a phenotype including mental retardation and ocular defects. Am. J. Med. Genet. A. 155A, 725-731. https://doi.org/10.1002/ajmg.a.33758

Jang, W., Chae, H., Kim, J., Son, J.-O., Kim, S.C., Koo, B.K., Kim, M., Kim, Y., Park, I.Y., Sung, I.K., 2016. Identification of small marker chromosomes using microarray comparative genomic hybridization and multicolor fluorescent in situ hybridization. Mol. Cytogenet. 9. https://doi.org/10.1186/s13039-016-0273-5

Kulikowski, L.D., Christ, L.A., Nogueira, S.I., Brunoni, D., Schwartz, S., Melaragno, M.I., 2006. Breakpoint mapping in a case of mosaicism with partial monosomy 9 p23 $\rightarrow$ pter and partial trisomy 1q41 $\rightarrow$ qter suggests neo-telomere formation in stabilizing the deleted chromosome. Am. J. Med. Genet. A. 140A, 82-87. https://doi.org/10.1002/ajmg.a.31045

Lenzini, E., Leszl, A., Artifoni, L., Casellato, R., Tenconi, R., Baccichetti, C., 1988. Partial duplication of 17 long arm. Ann. Genet. 31, 175-180.

Li, C., Chen, B., Zheng, J., Cheng, L., Song, T., Guo, F., Xu, H., Yan, F., Xu, Y., Li, Y., Zhang, J., 2019. Prenatal Diagnosis of BACs-on-Beads Assay in 3647 Cases of Amniotic Fluid Cells. Reprod. Sci. Thousand Oaks Calif 26, 1005-1012. https://doi.org/10.1177/1933719118804416

LI, H., LI, Y., ZHAO, R., ZHANG, Y., 2019. Cytogenetic Analysis of Amniotic Fluid Cells in 4206 Cases of HighRisk Pregnant Women. Iran. J. Public Health 48, 126-131.

Lin, S.-Y., Lee, C.-N., Peng, A.-Y., Yuan, T.-J., Lee, D.-J., Lin, W.-H., Ma, G.-C., Chen, M., 2018. Application of molecular cytogenetic techniques to characterize the aberrant $Y$ chromosome arising de novo in a male fetus with mosaic $45, X$ and solve the discrepancy between karyotyping, chromosome microarray, and multiplex ligation dependent probe amplification. J. Formos. Med. Assoc. Taiwan Yi Zhi 117, 1027-1031. https://doi.org/10.1016/j.jfma.2018.04.011

Liu, Q., Karolak, J.A., Grochowski, C.M., Wilson, T.A., Rosenfeld, J.A., Bacino, C.A., Lalani, S.R., Patel, A., Breman, A., Smith, J.L., Cheung, S.W., Lupski, J.R., Bi, W., Stankiewicz, P., 2020. Parental somatic mosaicism for CNV deletions - A need for more sensitive and precise detection methods in clinical diagnostics settings. Genomics 112, 2937-2941. https://doi.org/10.1016/j.ygeno.2020.05.003 
Malvestiti, F., Agrati, C., Grimi, B., Pompilii, E., Izzi, C., Martinoni, L., Gaetani, E., Liuti, M.R., Trotta, A., Maggi, F., Simoni, G., Grati, F.R., 2015. Interpreting mosaicism in chorionic villi: results of a monocentric series of 1001 mosaics in chorionic villi with follow-up amniocentesis. Prenat. Diagn. 35, 1117-1127. https://doi.org/10.1002/pd.4656

Pipiras, E., Dupont, C., Chantot-Bastaraud, S., Siffroi, J.P., Bucourt, M., Batallan, A., Largillière, C., Uzan, M., Wolf, J.P., Benzacken, B., 2004. Structural chromosomal mosaicism and prenatal diagnosis. Prenat. Diagn. 24, 101-103. https://doi.org/10.1002/pd.797

Popovic, M., Dhaenens, L., Boel, A., Menten, B., Heindryckx, B., 2020. Chromosomal mosaicism in human blastocysts: the ultimate diagnostic dilemma. Hum. Reprod. Update 26, 313-334. https://doi.org/10.1093/humupd/dmz050

Ruiz-Herrera, A., García, F., Mora, L., Egozcue, J., Ponsà, M., Garcia, M., 2005. Evolutionary conserved chromosomal segments in the human karyotype are bounded by unstable chromosome bands. Cytogenet. Genome Res. 108, 161-174. https://doi.org/10.1159/000080812

Serotkin, A., Stamberg, J., Waber, L., 1988. Duplication 17q mosaicism: an infant with features of Ellis-van Creveld syndrome. J. Med. Genet. 25, 258-260. https://doi.org/10.1136/jmg.25.4.258

Sifakis, S., Koukoura, O., Mantas, N., Velissariou, V., Koumantakis, E., 2008. Hydrops fetalis, thickened placenta and other sonographic findings in a low-level trisomy 21 mosaicism: a case report. Fetal Diagn. Ther. 24, 310-312. https://doi.org/10.1159/000160218

Stallings, R., Vaughn, D., Hall, K., Joyce, C., Ryan, F., Barton, D., Geraghty, M., 1997. Mosaicism for trisomy $3 q$ arising from an unbalanced, de novo t(3;15). J. Med. Genet. 34, 512-514. https://doi.org/10.1136/jmg.34.6.512

Taylor, T.H., Gitlin, S.A., Patrick, J.L., Crain, J.L., Wilson, J.M., Griffin, D.K., 2014. The origin, mechanisms, incidence and clinical consequences of chromosomal mosaicism in humans. Hum. Reprod. Update 20, 571-581. https://doi.org/10.1093/humupd/dmu016

Tidrenczel, Z., Tardy, E.P., Pikó, H., Sarkadi, E., Böjtös, I., Demeter, J., Simon, J., Kósa, J.P., Beke, A., 2019. Prenatal Diagnosis of $4 q$ Terminal Deletion and Review of the Literature. Cytogenet. Genome Res. 158, 63-73. https://doi.org/10.1159/000500735

Tuke, M.A., Ruth, K.S., Wood, A.R., Beaumont, R.N., Tyrrell, J., Jones, S.E., Yaghootkar, H., Turner, C.L.S., Donohoe, M.E., Brooke, A.M., Collinson, M.N., Freathy, R.M., Weedon, M.N., Frayling, T.M., Murray, A., 2019. Mosaic Turner syndrome shows reduced penetrance in an adult population study. Genet. Med. Off. J. Am. Coll. Med. Genet. 21, 877-886. https://doi.org/10.1038/s41436-0180271-6

Vanneste, E., Voet, T., Le Caignec, C., Ampe, M., Konings, P., Melotte, C., Debrock, S., Amyere, M., Vikkula, M., Schuit, F., Fryns, J.-P., Verbeke, G., D’Hooghe, T., Moreau, Y., Vermeesch, J.R., 2009. Chromosome instability is common in human cleavage-stage embryos. Nat. Med. 15, 577-583. https://doi.org/10.1038/nm.1924

\section{LEGENDS TO FIGURES}

Figure 1: Fetal karyotype on cultured amniocytes demonstrating the co-existence of 2 cell lines in the fetus. Panel (A): karyotype of a metaphase with the del(4)(q33), indicated by the arrow. Panel B: karyotype of a metaphase with the $\operatorname{der}(4) \mathrm{t}(4 ; 17)(q 33 ; q 11)$ chromosome, indicated by the arrow.

Figure 2: aCGH profile obtained from frozen fetal muscle DNA. Panel (A): 4q33qter non-mosaic heterozygous loss. Panel (B): normal chromosome 17 profile.

Figure 3: M-FISH results on cultured amniocytes. Panel (A): karyotype of a metaphase with the del(4)(q33). Panel (B): karyotype of a metaphase with the $\operatorname{der}(4) t(4 ; 17)(q 33 ; q 11)$ chromosome. 
381 Figure 4: Schematic representation of the hypothesized mechanisms leading to the mosaic chromosomal 382 rearrangement. Pane $(A): \operatorname{der}(4) t(4 ; 17)$ breakage and neotelomere formation. Pane (B): DSB at 383 chromosome $4 q 33$ and aberrant MMBIR using a chromosome 17 template. Pane $(C): t(4 ; 17)$ with 384 formation of a dicentric der(4) and loss of the der(17) acentric fragment, followed by secondary der(4) 385 breakage in one cell line. Pane (D): chromoanagenesis. Fragmentation of one chromosome 4 and one 386 chromosome 17. Chromoanagenesis rescue generates a major cell line with a fully recovered chromosome 38717 and an isolated 4qter deletion, and a minor cell line where the long arm of chromosome 17 replaces the 388 4qter segment. The 4qter segment and chromosome 17 short arm are lost and the monosomy 17 is 389 rescued. 
Figure 1

A

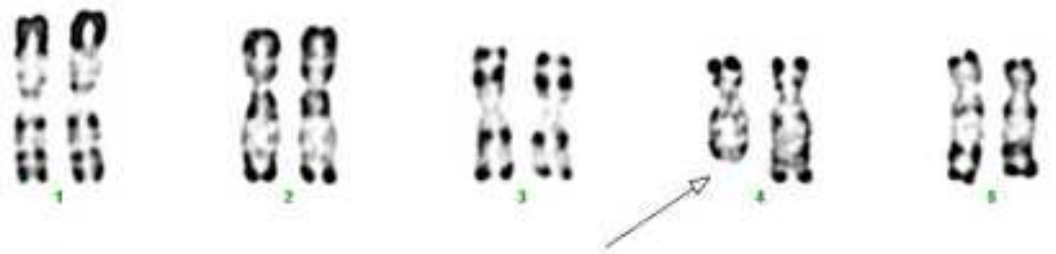

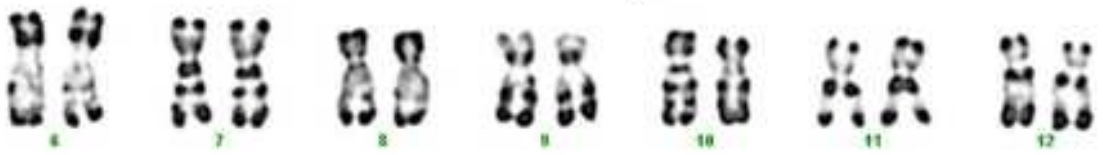

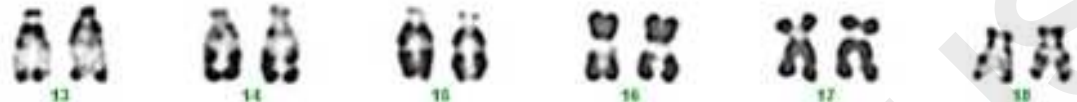

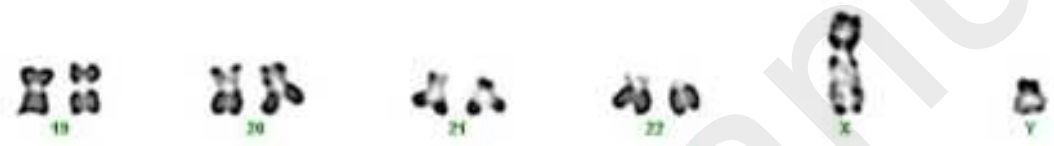

B

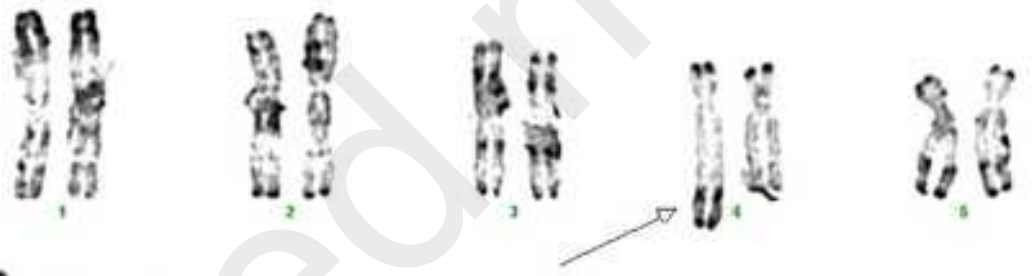

से

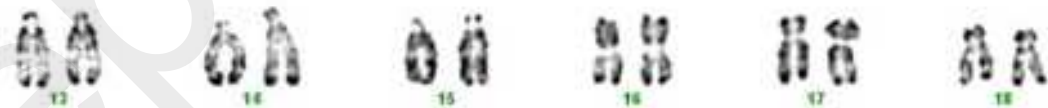

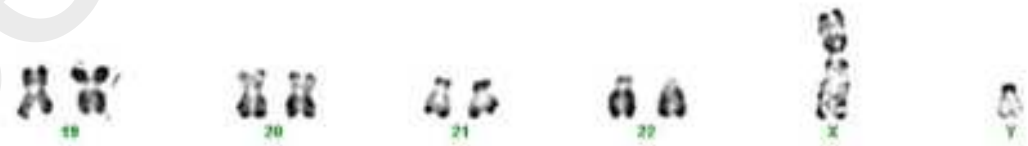


Figure 2

A
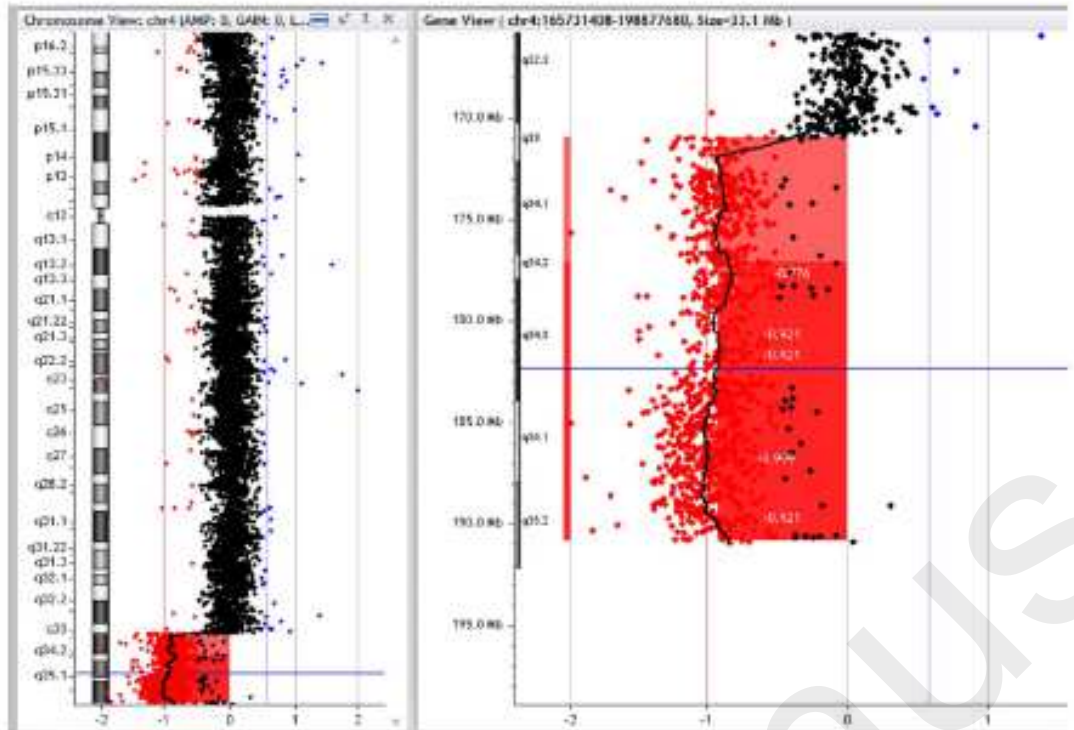

B

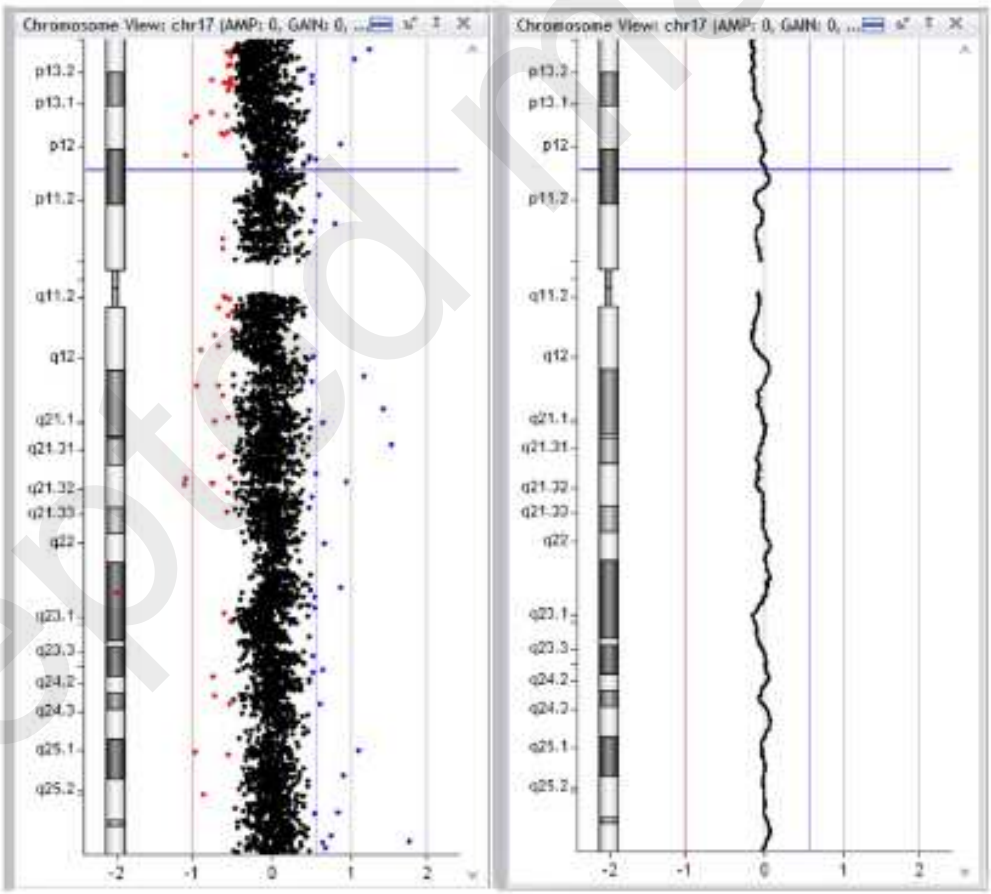


Figure 3

A

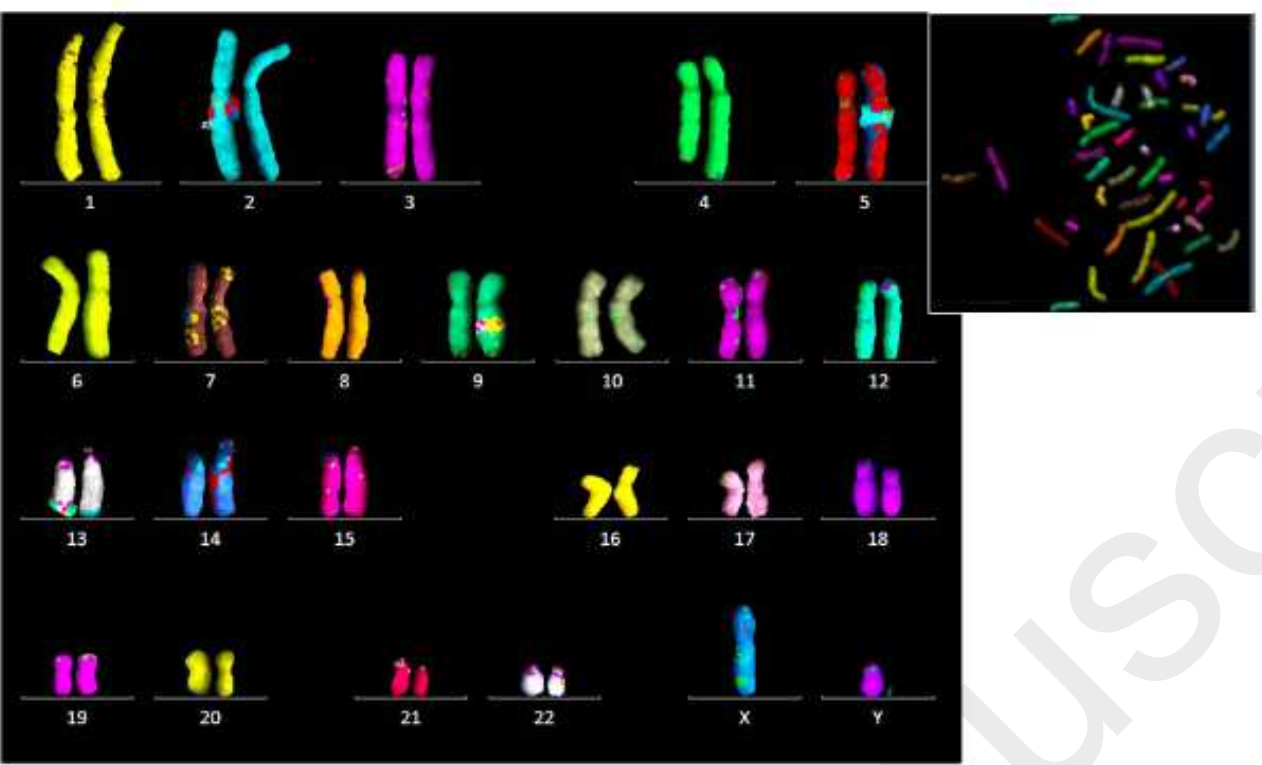

B

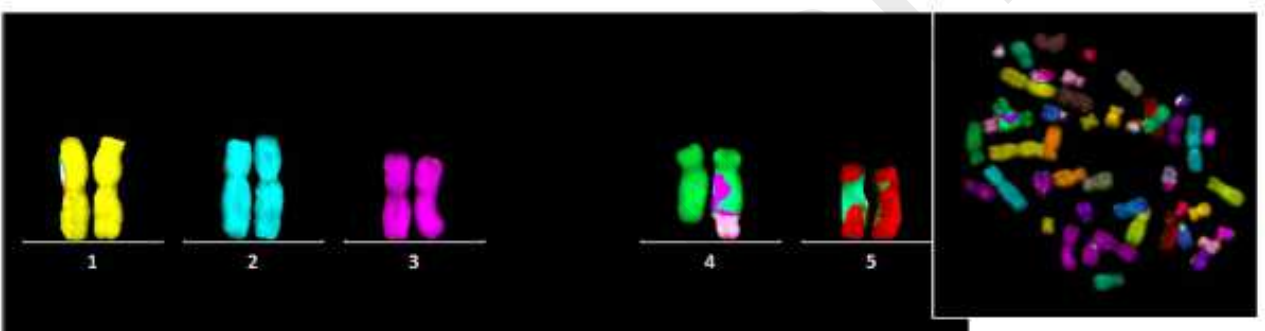

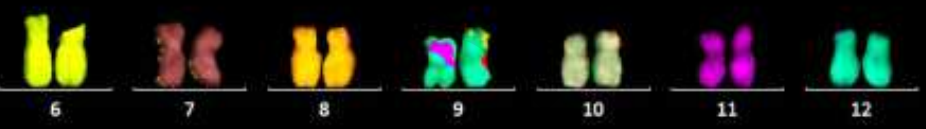

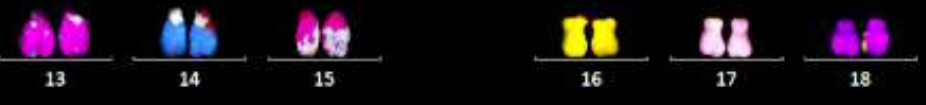

395

396 
A

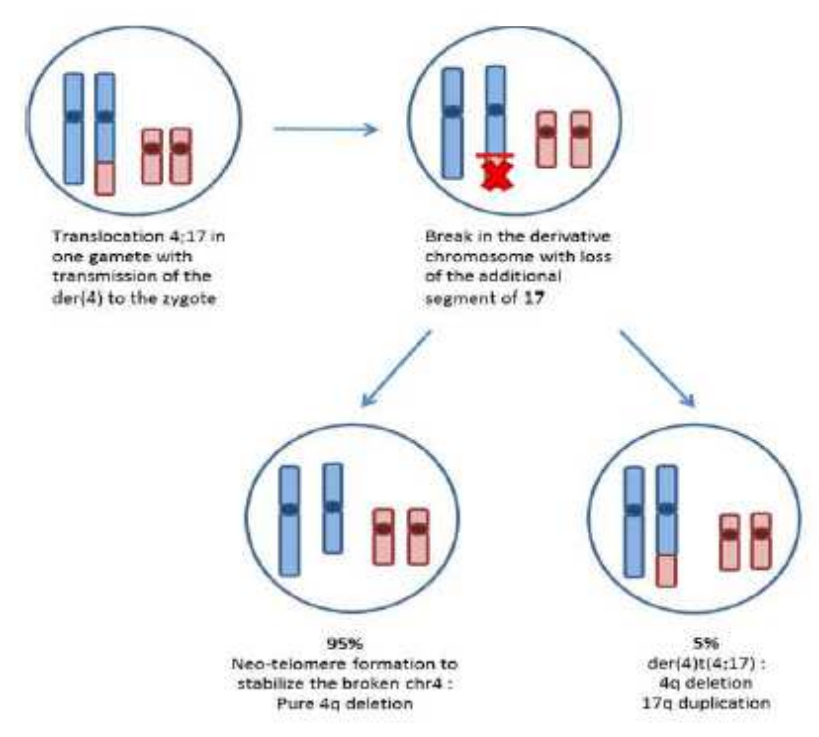

C
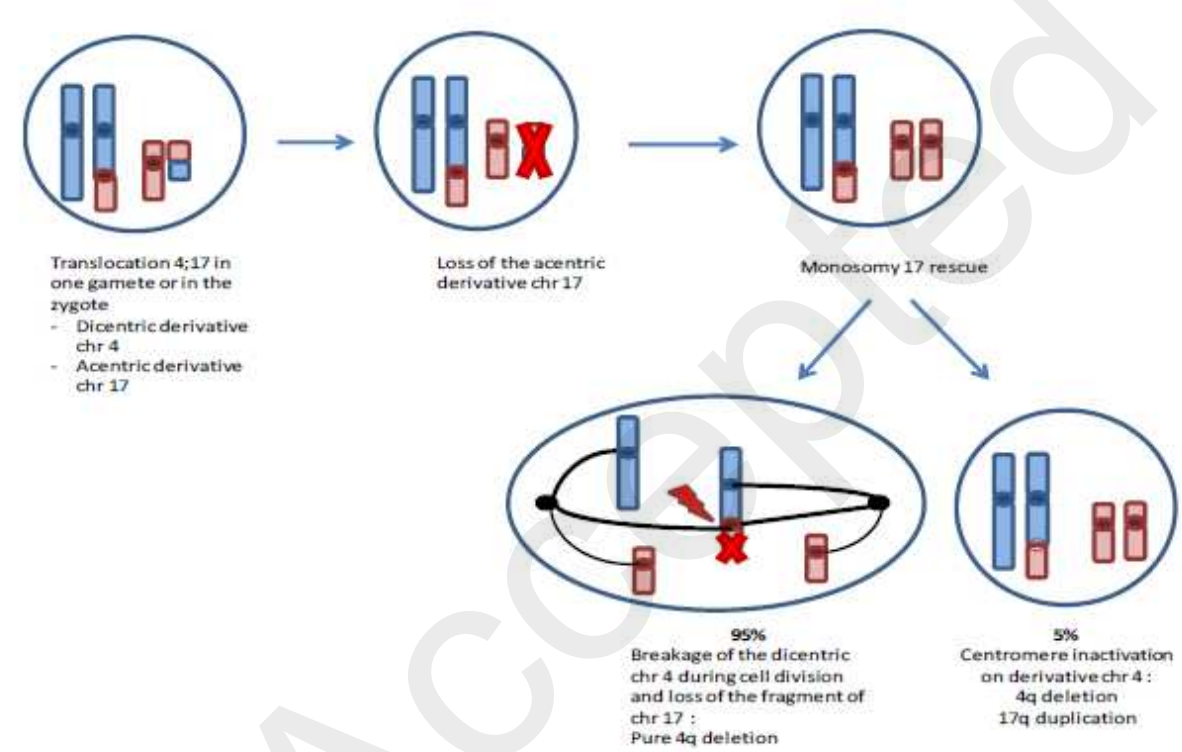

B
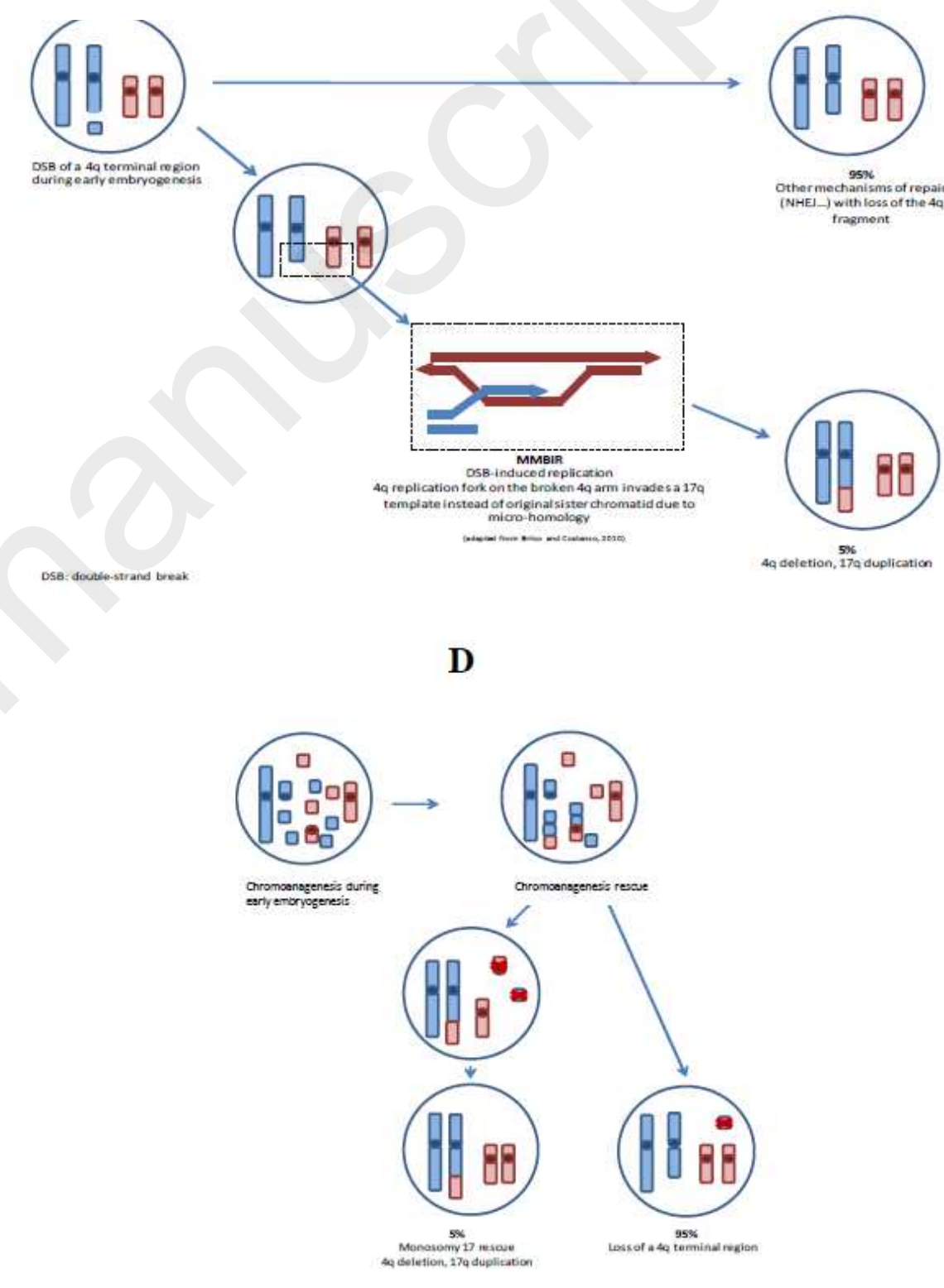